\title{
Entre América y Europa. Tocqueville y la historia del concepto de democracia
}

\author{
Between America and Europe. Tocqueville and the \\ History of the Concept of Democracy
}

\author{
Sandro CHIGNOLA \\ Universidad de Padua \\ sandro.chignola@unipd.it
}

Recibido: 28/06/2013

Aceptado: 20/02/2014

\section{Resumen}

El presente artículo trata acerca de las obras de Alexis de Tocqueville como una contribución a la historia de los conceptos de individuo y gobernancia. La democracia no es una forma de gobierno, como es concebida por la tradición política, sino una tendencia que marca la nueva condición del mundo, es el problema de los tiempos modernos que fuerza una renovación de categorías y conceptos para una teoría de gobierno.

Palabras clave: Tocqueville, democracia, historia de los conceptos políticos, individuo, gubernamentalidad.

\begin{abstract}
This article focuses on the works of Alexis de Tocqueville as a contribution to the history of the concepts of individual and governance. Democracy is not a form of government, as conceived in the political tradition, but a tendency that marks the new condition of the world, the problem of modern times which forces the renewal of categories and concepts for a theory of government.

Keywords: Tocqueville, democracy, history of political concepts, individual, governamentality.
\end{abstract}


¿Qué implica "democracia" en el uso tocquevilleano del término "democracia"? ¿Podemos pensar que la lógica de la democracia, por cómo esta se expresa en el pensamiento político occidental, expresa una misma tensión significante? ¿Podemos referirnos a la historia de la filosofía política como la línea dibujada por la vuelta a una misma cuestión? ¿Por qué volver a Tocqueville? ¿Quizá porque el nombre de Tocqueville es el de un "clásico" respecto a la historia del concepto de democracia? Y, entonces, de manera más precisa: ¿Qué significa afrontar la Démocratie en Amérique como un "clásico"?

1. Se podría pensar que mi intención sea la de intentar volver a poner en el centro de la atención de los estudiosos a un autor olvidado con demasiada rapidez. Como si el estudio de la historia del pensamiento político o la historia de la filosofía política requiriera una curiosidad de anticuario; el gusto por "redescubrir" o "celebrar". Como si se mantuviese en tensión por intentos dirigidos fundamentalmente a la rehabilitación o, como alguien ha propuesto explícitamente en Italia, a la simple depredación o "saqueo". Es decir, al objeto de recuperar elementos que se puedan reinsertar en la teoría política contemporánea del "tesoro" de los textos de la tradición. No es esta, sin embargo, mi intención.

Retorno a Tocqueville porque considero no tanto que tiene algo que decirnos respecto al modo en el cual se ha desarrollado, o puede aún desarrollarse, nuestra historia, sino porque pienso que Tocqueville es realmente un "clásico". La de Tocqueville no es la voz de un profeta. La voz de quien habría podido prever en la democracia americana -como una crítica más bien obsoleta ha teorizado-el perfil del espectro de la sociedad de masas, o de quien nos puede mostrar, sobre el ejemplo del federalismo americano, cómo deberíamos quizá organizar la constitución europea ${ }^{2}$. Tocqueville es un "clásico" porque las cuestiones que plantea son aún las nuestras. Nos obligan verdaderamente a enfrentarnos con ellas.

¿Qué significa pensar la democracia como tendencia y, por tanto, más allá del tranquilizador cuadro de las formas de gobierno? ¿Qué comporta el advenimiento del individuo moderno y la disgregación de la sociedad en clases? ¿Cómo recomponer la

\footnotetext{
${ }^{1} \mathrm{~S}$. Veca, Kant e il paradigma della teoria della giustizia, en: G. M. Chiodi, G. Marini, R. Gatti (eds.), La filosofia politica di Kant, Milano, Franco Angeli, 2001, pp. 143-52. Las obras de Alexis de Tocqueville se citan por la edición de las Oeuvres complètes de Alexis de Tocqueville, Paris, Gallimard, según las siguientes siglas: De la démocratie en Amérique, I, 1835 (DAI); De la démocratie en Amérique, II, 1840 (DAII); L’Ancien régime et la Rèvolution, 1856 (ARER); Mélanges (M); Ecrits et discours politiques (EDP).

${ }^{2}$ El pasaje podría ser analizado, por ejemplo, en las continuidades estructurales y argumentativas que existen entre los dos libros de L. Siedentop: Tocqueville, New York and London, Oxford UP, 1994; y Democracy in Europe, New York, Columbia UP, 2001.
} 
déliason que descompone los cuadros de la ciudadanía, deshace cualquier forma consolidada de vínculo social, aísla a los individuos, unos de otros, y convierte su antagonismo en permanente? ¿Cuál es el significado del nacimiento sincrónico y lógicamente necesario de la soberanía del pueblo y la centralización administrativa ${ }^{3}$ ? ¿Qué significa la afirmación, según la cual, en el antiguo régimen no existía la idea de "sociedad" 4 ? Son estas las cuestiones fundamentales que Tocqueville se plantea. Y que nos replanteamos también nosotros a partir de la lectura de sus escritos.

Creo que el trabajo histórico sobre los textos de la filosofía política o el análisis del discurso político, cuando este último se realiza en términos históricos, no tienen nada que ver ni con la curiosidad anticuaria ni con intenciones monumentales. Ciertamente, los autores no trabajan para su propia canonización en el panteón de los "clásicos". A menudo, por el contrario, el significado de las obras de los pensadores políticos, su significado para nosotros que los leemos desde un tiempo lejano, no se puede hallar en el hecho de que en ellas se haya condensado la experiencia de una época histórica, el "espíritu" de esta última. Ese significado, en cambio, puede verificarse sólo en el desafío que estos textos plantean a los lugares comunes que recorren a esta época histórica, al proceder desestabilizador que estos realizan respecto a esa experiencia, al modo en el cual todo lo que parece evidente se pone en discusión y la realidad es indagada según un modo de mirar radicalmente nuevo 5 .

Un "clásico", según lo entiendo yo, es un texto en el cual se deposita una radical interrogación respecto a la legitimidad de las categorías tradicionalmente aplicadas a la investigación sobre la política, y de esos conceptos más difundidos y consolidados se reconstruye su genealogía y se investigan sus aporías. "Clásica", dicho en otros términos, es una obra en la cual se realiza una radical desestabilización de los circuitos de la formalización y lo que se considera evidente y, por así decirlo, cierto, es invadido por la duda y despojado de su presunta autoevidencia.

En Tocqueville, este movimiento de apertura es totalmente consciente. Escribe es necesaria una ciencia política nueva para un mundo totalmente nuevo ${ }^{6}$. Todo lo que la democracia - pensada como proceso de la igualdad, como movimiento social irresistible y de larga duración que disuelve formas institucionales y vínculos sociales, que revoluciona los órdenes de la "antigua constitución europea", como Tocqueville la llamará en el Ancien régime et la Révolution", y que aísla a los hombres los unos

\footnotetext{
${ }^{3}$ Discours de M. de Tocqueville pronocé dans la séance publique du 21 avril 1842, en venant prendre séance à la place de M. le Comte de Cessac, M, p. 262.

${ }^{4}$ DAII, IV, cap. 7, p. 334.

${ }^{5}$ Q. Skinner, Meaning and Understanding in the History of Ideas, ahora en: J. Tully, Meaning and Context. Quentin Skinner and his Critics, Oxford, Polity Press, 1988, pp. 29-67.

${ }^{6}$ DAI, Introduction, p. 5: "Il faut une science politique nouvelle à un monde tout nouveau".

${ }^{7}$ ARER, I, cap. 4.
} 
de los otros radicalizando hasta el extremo la lógica disociativa que preside la moderna identificación del sujeto de derecho- hace pensar es el hecho de que estamos inexorablemente entrando en otra época de la historia. En la cual los viejos conceptos y las viejas prácticas políticas y de pensamiento se demuestran obsoletos y fuera de uso ya. Del todo, inutilizables.

El proceso de igualdad, la democracia, es, para Tocqueville, una revolución, un hecho providencial capaz de encaminar hacia su propia realización todas las circunstancias externas, los hechos de la historia, demostrándose irreductible a la suspensión e incontenible respecto a la adopción de cualquier esquema analítico que pueda derivarse de la experiencia. No hay precedente utilizable, espacio comparativo posible, para una reflexión que asuma, hasta el fondo, las características de la democracia de universalidad, constancia e imposibilidad de ser quebrantada ${ }^{8}$. Y exactamente esta consciencia es, creo yo, la que impulsa a Tocqueville a ir más allá de los esquemas del liberalismo doctrinario francés. El abandono de Francia -independientemente de las circunstancias del viaje- es todo lo que a Tocqueville se le revela necesario en el momento exacto en el cual percibe como definitivamente superada la conexión entre los tiempos históricos, la pacificación entre lo antiguo y lo moderno, a la cual Guizot había considerado posible confiar, en cambio, la tarea de "cerrar" la larga transición francesa.

2. No es por casualidad que Guizot, haciendo referencia a la historia, intentara circunscribir un tranquilizador espacio comparativo para la teoría política. En el paradigma de la "histoire resurrection", según la cual el esfuerzo del historiador de recomposición debe dirigirse a la representación de la viviente organicidad del presente-pasado y no a la árida enumeración de hechos o al aislamiento de esquemas pronósticos y de leyes evolutivas, el tableau del evento histórico puede ser restituido adecuando su intrínseca complejidad interna a la figura de todo lo que ha sucedido efectivamente. La potencia morfogenética de la historia, el choque de intereses, el campo de los antagonismos sociales, pueden mantenerse así y restituirse al lector como depuraciones de los vectores de fuerza que habían identificado las características de presente en tensión, proyectado, con todas sus contradicciones, en dirección a un futuro abierto. Resucitar el presente-pasado, significa para Guizot, poner al lector -o a quien asistía, como lo hacía Tocqueville, a sus cursos en la Sorbonne ${ }^{9}$ - frente a la evidencia del presente. Ofrecerle la posibilidad de reflejar su propia imagen en el espejo tranquilizador del pasado ${ }^{10} \cdot$ ¿Qué podía existir más edificante, y más legitimador,

\footnotetext{
${ }^{8}$ DAI, Introduction, p. 4.

${ }^{9}$ Cf. Tocqueville, Notes sur le Cours d'histoire de la civilisation en France de Guizot (1829-1830), en: M, pp. 439-534.

${ }^{10}$ Guizot, Histoire de la civilisation en France, lecc. XI.
} 
para una ciencia de la historia con una explícita vocación política que volverse hacia el pasado para hallar en él, en presencia de una revolución constantemente replanteada y sin fin, el precedente de una revolución que había sabido llegar a cumplirse? ${ }^{11}$

Este es el camino de investigación emprendido por Guizot en la Histoire de la Révolution d'Angleterre. La Revolución inglesa enseña la posibilidad de encapsular el proceso social democrático en el cuadro de una "démocratie disciplinée" en la cual no se interrumpe el vínculo entre pueblo y aristocracia. En el espejo de la Revolución inglesa, es posible identificar el reflejo de una transición que ha tenido éxito. Y permite, por tanto, aislar los factores que pueden asegurar el mismo resultado.

Entre Francia e Inglaterra, es posible, para Guizot, delimitar un espacio protegido. Representar en tableau el vivo presente de una revolución, la inglesa, cuyo significado histórico coincide con un proceso de constitucionalización de los derechos fundamentales, que conecta el ascenso de las clases medias al tronco de una libertad de larga duración garantizada por la monarquía y por un complejo de instituciones en las cuales se sanciona ininterrumpidamente la solidez del pacto social entre el pueblo y las clases de la razón.

El presente resucitado por la ciencia histórica puede así ser reconfigurado en precedente normativo. La gloriosa revolución de 1688 custodia, en sí, el significado filosófico-histórico de la monarquía constitucional y permite imaginar la historia de Europa, aún, como unitaria ${ }^{12}$. Por un lado, se da un resultado de estabilidad progresiva, la sanción constitucional de los derechos fundamentales y del principio representativo. Por otro, aparece un vínculo que no se rompe nunca, durante todo el curso de la revolución, entre las clases populares y la aristocracia, auténtica intérprete y custodia natural de los intereses de la nación.

Guizot encierra el paralelismo entre Francia e Inglaterra dentro del juego de espejos entre presente y pasado. La analogía entre las dos revoluciones, instruida por la ciencia histórica con el fin de recuperar el éxito inglés, es el modelo con el cual conformar la praxis político-constitucional de la Francia de la restauración. Este modelo permite imaginar transición entre lo viejo y lo nuevo como no taumática, y el compromiso entre democracia y aristocracia como nuevamente practicable. La evolución de la revolución inglesa celebra la constancia de la "hereux mélange" entre estos dos principios. Su siempre posible "harmonie" se da en un orden social cuyas dinámicas evolutivas nunca llegan al punto de separar, irremediablemente, pasado y futuro. En las clases aristocráticas, el pueblo reconoce la propia guía natural. En el pueblo, la aristocracia encuentra la instancia de movimiento capaz de mantener en progreso a la historia: orden $y$ progreso. La libertad reconfigura y adapta las instituciones a un

\footnotetext{
${ }^{11}$ Guizot, De la démocratie en France, Paris, Plon, 1849.

${ }^{12}$ Sobre el tema, cf. F. Furet, Burke et la fin d'une seule histoire d'Europe, "Le Débat", 39, 1986, pp. 56-66.
} 
tiempo nuevo, sin por ello desencadenar incontenibles derivas anárquicas ${ }^{13}$. La precedente de una revolución como "acte de pure défense" ${ }^{14}$ para una Revolución como la francesa posee la legitimidad de resarcir el déréglement constitucional de la monarquía absoluta. El sueño de una "democratie disciplinée" estará, pues, ya siempre organizada por las clases sociales de la capacidad y de la razón.

3. La elección de embarcarse hacia América que tomó Tocqueville es una elección coherente con su necesidad de replantear el problema de la democracia fuera y más allá de la pantalla protectora ofrecida por el comparativismo histórico. Para comprender la democracia -auténtico nuevo estado del mundo, dinámica sin aparente motor de una igualdad que se plantea como el nuevo "fait générateur" de toda la fenomenología político-social de la época moderna- es necesario un drástico paso hacia el futuro. El movimiento de Tocqueville es ponerse sobre las huellas de una tendencia que impulsa hacia una travesía compleja por el presente. Una travesía que debe recuperar por sí misma los propios instrumentos de orientación, porque ninguna garantía puede ya provenir de las ciencias históricas. Tocqueville escribe: "Car déjà les termes de comparaison nous manquent" ${ }^{15}$.

El viaje a América marca la ruptura no sólo con el modelo historiográfico de Guizot sino también, y sobre todo, con el proyecto doctrinario de estabilización de la sociedad francesa. Por un lado, realiza la interpretación de la revolución de 1789 como actualización de los equilibrios constitucionales en las nuevas condiciones sociales. Plasma la idea de la necesidad del paso revolucionario, esto es, como rodeo del bloque producido por la deriva absolutista de la monarquía y como reintegración de la historia institucional francesa en la línea ascendente de la historia liberal europea. Por el otro, materializa el proyecto de una crítica del voluntarismo político que actúa como matriz fundamental -entre absolutismo y Revolución- para el moderno concepto de soberanía. El correlato de este concepto moderno de soberanía es una noción abstracta de representación política que monopoliza la legitimidad y que proscribe la posibilidad de un equilibrio entre los poderes ${ }^{16}$.

Para Guizot, el compromiso entre democracia y aristocracia se realiza como adopción del principio representativo -esfera pública, transparencia y responsabilidad de la acción ministerial y monarca como símbolo de la unidad de la Nación- y su tor-

\footnotetext{
${ }^{13}$ Guizot, Histoire de la Révolution d'Angleterre (1826), edición establecida por L. Theis, Paris, Laffont, 1997, Discours sur la Révolution d'Angleterre, pp. 68-69.

${ }^{14}$ Ibidem, p. 67.

${ }^{15}$ DAI, Introduction, p. 4.

${ }^{16}$ Guizot, Philosophie politique: de la souveranité (1826), en Histoire de la civilisation en Europe. Depuis la chute de l'Empire romain jusqu'à la Révolution française, edición establecida, presentada y anotada por P. Rosanvallon, Paris, Hachette, 1985, pp. 343-344.
} 
sión en sentido "sociológico". Lo que se representa no es la voluntad, mucho menos la de los individuos, sino el "estado" del avance de la civilización en la escala filosófico-histórica de la movilidad ascendente de las clases medias, valorándolo en la "capacidad" de las profesiones y de las propiedades que "representan" a la sociedad en la medida en que expresan naturalmente el más auténtico, y maduro, "interés" de esta última ${ }^{17}$.

La representación no transmite formalmente una voluntad in-diferente -perno necesario sobre el cual gira el reconocimiento constitucional del principio de igualdad que informa de sí misma a la época moderna-, sino que adecúa, en términos reflexivos, el gobierno al grado de la evolución social, "recogiendo" todo lo que la sociedad expresa como la propia dinámica de avance y progreso. La evolución social es imaginada por Guizot, por tanto, como ininterrumpidamente gobernada. Y el principio de representación se funda sobre la "capacité" de una aristocracia liberal de las profesiones y del comercio que permite la reproducción de la sociedad a través de un sistema de articulaciones y de diferencias. Estas articulaciones y diferencias son legítimas porque están basadas sobre el simple reconocimiento de un mérito, y son conservadas y recompuestas en la sociedad, adaptándolas a un ritmo de progreso ordenado.

Es la misma idea de este compromiso entre aristocracia y democracia, entre los principios que conforman -y separan- dos épocas, drásticamente diferentes de la historia, lo que Tocqueville rechaza. Su partida hacia el Nuevo mundo representa, en términos casi de figuras, la renuncia a llevar consigo, mientras nos aventuramos en el futuro, instrumentos de análisis o categorías recuperadas del pasado. Para Tocqueville, es inimaginable que la gran revolución social de la igualdad, en marcha desde hace siglos, tras haber arrollado al feudalismo y al mundo nobiliario, pueda detenerse ante la aristocracia de la riqueza ${ }^{18}$. Que la teoría política conciliatoria y compromisoria del liberalismo pueda conseguir el milagro de bloquear el tiempo y de estabilizar la transición, simplemente reanudando en las Charte el pacto entre monarquía y Nación es idea que acota el futuro al pasado mañana. Y que considera que se puede diferir, indefinidamente, una tregua con el nuevo tiempo, que ha caducado ya. Tocqueville señala: “Tandis qu'ils s'occupent du lendemain, j'ai voulu songer à l'avenir" ${ }^{\prime 1}$. Es este, contra los doctrinarios, el movimiento de apertura de Tocqueville.

4. Aquí estamos, por tanto. ¿Qué es, entonces, la democracia? ¿A qué corresponde el "état social" de la nueva configuración del mundo? Democracia no es una forma de gobierno y las fórmulas institucionales a las cuales ésta da lugar no tienen,

\footnotetext{
${ }^{17}$ Sobre la teoría de la representación en Guizot, cf. L. Jaume, "Guizot et la philosophie de la représentation", Droits, 15, 1992, pp. 141-152.

${ }^{18}$ DAI, Introduction, p. 4.

${ }^{19}$ DAI, Introduction, p. 14.
} 
aparentemente, fundamento. Tocqueville lleva a cabo un segundo paso más allá de las columnas de Hércules de la teoría política ${ }^{20}$. Tocqueville afina una definición tendencial de la democracia. La asume como indicador de movimiento. Democracia es el término que intenta denominar la revolución social de la igualdad, el proceso que erradica el privilegio y que desarticula el valor social de las diferencias. La democracia no denota, para Tocqueville, una fórmula institucional, sino un nuevo estado de la sociedad.

Es interesante, $\mathrm{y}$, al menos en mi opinión, decisivo, que Tocqueville acredite la modernidad del cuño de dos conceptos, al menos, que no se pueden encontrar en el antiguo régimen. Por un lado, el concepto de "sociedad", por el otro el de "individuo". En el antiguo régimen no puede ser pensado un objeto vacío, formalizable desde el exterior, como la sociedad, porque no existe una función de subjetividad serial, que los "individuos" puedan recomponer en un espacio de acción asumido como genérico y general. La constitución por clases conoce un policentrismo de poderes y de formaciones sociales que hace indisponible el aislamiento y la construcción de un objeto "sociedad", escindido por el sistema de relaciones sobre el cual se sostiene la articulación constitucional. Nobles, clases, corporaciones, parlamentos, ciudades unen a los humanos y articulan el sistema de diferencias que estructura sus relaciones "sociales" en términos que son, ya desde siempre, "políticos". No hay separación entre sociedad y Estado en la antigua societas civilis europea ${ }^{21}$. Y no hay "individuos", porque el individualismo moderno puede producirse solo como valorización de un aislamiento pre-político de individuos literalmente impensable en el imbriquement de relaciones civiles-políticas del antiguo régimen ${ }^{22}$.

Nadie está "solo" ${ }^{23}$, en la antigua constitución europea, porque se incorpora a ella desde el sistema de vínculos y de concretos intereses que lo identifican con un grupo

\footnotetext{
${ }^{20}$ Como John Stuart Mill señaló en la Edinburgh Review (LXII, oct. 1840, 1-47) reseñando a DAII, el de Tocqueville se demuestra, precisamente por este tipo de motivos, como el "primer libro filosófico sobre la democracia" que se haya escrito nunca. Cf. J. S. Mill, Essais sur Tocqueville et la société américaine, edición y prefacio de P. Thierry, Paris, Vrin, 1994, p. 145.

${ }^{21}$ Sobre la noción clasista de societas civilis: M. Riedel, Gesellschaft, Bürgerliche, en O. Brunner, W. Conze, R. Koselleck (eds.), Geschichtliche Grundbegriffe. Historisches Lexikon zur politischsozialen Sprache in Deutschland, Stuttgart, Klett-Cotta, vol. 2, 1975, pp. 719-800; P. Kondylis, Konservativismus. Geschichtlicher Gehalt und Untergang, Stuttgart, Klett-Cotta, 1986.

${ }^{22}$ Para la introducción del término "individualismo" en el léxico político del siglo XIX, véanse: K. W. Swart, "Individualism" in the Mid-Nineteenth Century (1826-1860)", Journal of the History of Ideas, XXIII, 1962, 1, pp. 77-90; S. Lukes, "The Meaning of 'Individualism"”, Journal of the History of Ideas, XXXII, 1971, 1, pp. 45-66; S. Lukes, Individualism, Oxford, Blackwell, 1973; C. Cassina, "Appunti intorno alle origini di una parola, individualismo", Cromohs, 1, 1996, pp. 1-21, http://www.unifi.it/riviste/cromohs/1_96/cassina.html.

${ }^{23}$ ARER, II, cap. 9.
} 
y que obtienen el campo de lo común. Esta incorporación no se produce como efecto espacial de una distancia (la que permite la individualización de los sujetos), sino como lugar de concurrencia, de la asociación y del reconocimiento, de expectativas, intereses y deberes diferenciados los unos respecto de los otros ${ }^{24}$.

Es, por tanto, el principio de diferencia, asumido en términos inmediatamente políticos, lo que impide pensar la individualización y, contemporáneamente, la sociedad como espacio de acción genérico para subjetividades abstractas y, como lo son las modernas, literalmente sin cualidades. La "revolución social" de la igualdad, la democracia, es, para Tocqueville, el proceso que permite trazar la genealogía de la moderna individuación de las relaciones político-sociales. "Individuo" y "sociedad" son nombres colectivos, dos de aquellas ideas generales que él adscribe directamente al "cartesianismo" implícito de la democracia ${ }^{25}$.

La democracia se instala, por tanto, en el corazón del razonamiento tocquevilleano -y no sólo, creo yo, en el dispositivo conceptual de De la démocratie en Améri$q u e-$ como aquello que identifica, en primer lugar, un inmanente proceso de disolución, de déliason. La democracia desliga, aísla, divide. Se connota como la constante reproposición de una individuación de las relaciones sociales que Tocqueville valora en términos sustancialmente patológicos.

Hay ahí un nexo, más bien evidente, entre el modo en el que él lleva el viaje americano -lleno de encuentros y de coloquios con expertos del ramo carcelario, como es bien conocido, sino también de foro de una colección de observaciones sobre las condiciones y la moralidad de las clases trabajadoras, sobre las dinámicas de la marginalización metropolitana, sobre al educación de los jóvenes, sobre la criminalidady el modo en que irá visitando, entre la redacción del primer y del segundo volumen de la Démocratie, Manchester y otros distritos núcleos obreros ingleses. ${ }^{26} \mathrm{La}$ democracia conlleva una revolución de las condiciones que guían la definición de las fun-

\footnotetext{
24 "Coetus" deriva del verbo "coire", "ir juntos", e indica la asamblea en que los hombres libres deliberan sobre lo que a todos concierne. Cf. E. Lousse, La société d'ancien régime, Louvain, Editions Universitaires, 1952; O. Brunner, Die Freiheitsrechte in der altständischen Gesellschaft, ahora en: Neue Wege der Verfassungs- und Sozialgeschichte, Göttingen, Vandenhoeck \& Ruprecht, 1968; O. Hintze, Typologie der ständischen Verfassungen des Abenlandes, ahora en: Gesammelte Abhandlungen, II, Soziologie und Geschichte, editado por G. Oestreich, Göttingen, Vandenhoeck \& Ruprecht, 1970, pp. 427-452.

${ }^{25}$ DAII, I, cap. 1, p. 11.

${ }^{26}$ Sobre el viaje americano de Tocqueville y sobre las bases a partir de las cuales se construye la Démocratie en Amérique: G. W. Pierson, Tocqueville and Beaumont in America, New York and London, Oxford UP, 1938; J. T. Schleifer, The Making of Tocqueville's Democracy in America, Chapel Hill, The University of North Carolina Press, 1980. Para los viajes ingleses: Tocqueville, Voyages en Angleterre et en Irlande, editado por J. P. Mayer, Paris, Gallimard, 1982. Sobre el tema: S. Chignola, "Noi, ultimi viaggiatori". Tocqueville e l'instabilità democratica", Contemporanea, II, 1, 1999, pp. 111-118.
} 
ciones de gobierno internas en el imbriquement político-social: con el avance inexorable de la ecualización, se vacía el peso social de la nobleza y de la nobleza local, se deshacen las redes de patronage entre patrón y trabajadores, entre visiteurs de pauvres y familias indigentes ${ }^{27}$. La democracia plantea los mismos problemas que la llamada cuestión social en aquella misma época. La democracia, al menos aparentemente, no estabiliza ningún sistema de gobierno. Y expresa, al contrario, dissociación y aislamiento.

¿Se puede, por tanto, pensar el gobierno de la democracia? El viaje a América se encarga de verificar esta posibilidad. Lo que maravilla a Tocqueville es no sólo el hecho de que sea posible una democracia de los grandes números, esto es que un país inmenso como América pueda ser descrito sólo adaptando la fórmula que la teoría política clásica consideraba que podía ser adaptada únicamente a pequeños países o ciudades. Le sorprende, sobre todo, el hecho de que la potencia expansiva de la democracia en ese país, como dinámica de movimiento, como fibrilación de los intereses y como perenne activación del deseo esté en condiciones de producir eficaces instituciones de autogobierno.

Hay países, escribe Tocqueville, en los cuales el poder, de alguna manera externo a la sociedad, actúa sobre esta última organizando sus procesos. En América, por el contrario, es la sociedad la que actúa directamente sobre sí misma, diseñando el plano de inmanencia para un intercambio político que no se sostenga en ninguna diferencia o exterioridad. El pueblo participa, a través de sus representantes, en el poder legislativo, pero influye directamente, en régimen de descentralización administrativa, también sobre la elección de los agentes del poder ejecutivo y toma parte, a través del jury, en el poder judicial. El pueblo reina sobre el mundo político americano como Dios sobre el universo, escribe Tocqueville: aquel es inicio y fin de cualquier $\operatorname{cosa}^{28}$.

Esta perfecta nivelación de la democracia se hace posible gracias al particularísimo "point de départ" de la colonización americana ${ }^{29}$. El "état social" americano está hecho de una comunidad socialmente homogénea -una misma persecución súbita, una misma fe, las mismas necesidades, una misma cultura- que se expande estabilizando un retículo de relaciones que produce y reproduce sociedades mientras se extiende por las praderas y avanza hacia el Oeste. El autogobierno democrático se

\footnotetext{
${ }^{27}$ Sobre el tema, véanse los ensayos ahora recogidos en: J. Rancière, Les scènes du peuple, Paris, Editions Horlieu, 2003; Cf. E. Keslassy, Le libéralisme de Tocqueville à l'épreuve du paupérisme, Paris, L'Harmattan, 2000; M. Tesini, Tocqueville e l'economia politica del suo tempo. Per un'introduzione agli scritti sul pauperismo, en: A. De Tocqueville, Il pauperismo, ed. de M. Tesini, Roma, EL, 1998, pp. 11-98.

${ }^{28}$ DAI, I, cap. 4, p. 56: “on peut dire qu'il gouverne lui même, tant la part laissée à l'administration est faible et restreinte, tant celle-ci se ressent de son origine populaire et obéit à la puissance dont elle émane".

${ }^{29}$ DAI, I, cap. 3.
} 
basa en un instinto asociativo natural, en el rechazo del principio de representación, cuando se trate del cuidado del interés común ${ }^{30}$, y sobre la defensa de una libertad que, desde el principio, no conoce delegaciones ni exclusiones por principio. Al menos entre los colonos blancos.

5. Aún más, no hay proletarios, en América ${ }^{31}$. La vuelta a Francia de Tocqueville coincide con el fin del espejismo de una inmediata auto-institución de lo social. Reflejada en el espejo americano, Francia parece encaminarse hacia un futuro inexorable -porque es efecto de una tendencia asumida como irresistible y universal-cuyas connotaciones parecen, sin embargo, más bien distintas. Es la constatación del efecto distorsionador producido por el reflejo de la tendencia democrática francesa en el espejo americano lo que conecta el primero y el segundo volumen de La démocratie en Amérique, ida y vuelta del viaje de Tocqueville ${ }^{32}$.

Si es distinto el "point de départ" de la igualdad, diversos serán de hecho los resultados de su proceso. En Francia, a diferencia de cuanto históricamente sucedió en América en los inicios de la colonización, "individuo" y "sociedad" no están inmediatamente disponibles y están, en cambio, producidos por la máquina absolutista. Creados por el trabajo de despolitización de la societas civilis. En América, igualdad y libertad son declinadas juntas desde el principio. Y representan por ello el motor de las instituciones y del autogobierno. En Francia, la igualdad es impuesta sobre las ruinas del sistema de clases de las libertates y es efecto de un proceso que se cumple bajo la mirada vigilante de los reyes ${ }^{33}$.

La liberación del individuo es, en Europa, empresa de la máquina absolutista ${ }^{34}$. Fruto de un dispositivo teórico que legitima la operación de la monarquía por medio de la proyección de los individuos sobre la escena del contrato social. Este es el descubrimiento de Tocqueville. Lo que libera a los individuos los unos de los otros, haciéndolos independientes del sistema de lealtades plurales y de articulados deberes de la constitución por clases, es el simultáneo y total sometimiento de todos al soberano, en el cual se representa la unidad del cuerpo político. Entre Hobbes y Rousseau, se diseña el entorno del acontecimiento que orienta la específica genealogía continen-

\footnotetext{
${ }^{30}$ DAI, I, cap. 5 , p. 60.

${ }^{31}$ DAI, II, cap. 6, p. 249: “En Amérique il n’y a point de prolétaires".

${ }^{32} \mathrm{Cf}$. M. Gauchet, Tocqueville, l'Amérique et nous. Sur la genèse des sociétés démocratiques, "Libre", nº 7, Paris, Payot, 1980.

${ }^{33}$ DAII, IV, cap. 4, p. 305: “Chez les Américains, c'est donc la liberté qui est ancienne; l'égalité est comparativement nouvelle. Le contraire arrive en Europe où l'égalité, introduite par le pouvoir absolu et sous l'œil des rois, avait déjà pénétré dans les habitudes des peuples longtemps avant que la liberté fut entrée dans leurs idées".

${ }^{34}$ Para la complejidad y las tensiones que marcan la noción tocquevilleana de "libertad": L. Jaume, Tocqueville. Les sources aristocratiques de la liberté, Paris, Fayard, 2008.
} 
tal del individualismo moderno: el sujeto de derecho se obtiene gracias a un mecanismo de sometimiento que no tiene ya nada de la dependencia clasista, porque se efectúa a favor de la forma abstracta y general de obligación que institucionaliza la reciprocidad de la individualización congelando la equidistancia de los súbditos, los unos de los otros, y de la instancia soberana en la cual se representa el singular colectivo de su unidad formal ${ }^{35}$. El mecanismo lógico del pacto permite compensar la despolitización de la societas civilis, la pulverización de los vínculos personales de dependencia de la sociedad feudal y el aislamiento, por tanto, de la singularidad, con la libertad "privada" de la cual cualquier sujeto de derecho es investido desde dentro del espacio general que el derecho se encarga de circunscribir como "sociedad".

Sólo en la perfecta equidistancia desde el centro -o de las instituciones que garantizan la aplicación de la ley y en el derecho mismo como forma en la cual se realiza la pre-condición categorial de su autodeterminación- los ciudadanos obtienen la posibilidad de transcribir su propia igualdad desde la premisa de la libertad común. La subordinación de todos los ciudadanos a la ley, cuando la ley es la expresión unitaria, producida en términos representativos, de su voluntad general, hace íntegramente libre al cuerpo político. "La ley es comparable al centro de una esfera inmensa" -escribe, exactamente en este sentido, el abad Sieyès- "sobre cuya superficie todos los ciudadanos, sin ninguna excepción, ocupan posiciones iguales equidistantes del centro; todos dependen del mismo modo de la ley, todos le confían la protección de sus libertades y sus propiedades; estos son para mi los derechos comunes de los ciudadanos, en virtud de los cuales estos se unen entre ellos" ${ }^{\prime 36}$. La afirmación de Sieyès -e implícitamente del pensamiento político del absolutismo, antes que él- es la verdad de la anotación tocquevilleana acerca del nacimiento simultáneo y lógicamente correlacionado de teorización de la soberanía popular y de la centralización administrativa ${ }^{37}$.

La continuidad entre absolutismo y Revolución francesa sobre la que Tocqueville insiste desde el ensayo sobre The Political and Social Condition of France, anticipada en $1836^{38}$, estratégicamente dispuesto entre los dos volúmenes de la Democracia en América, avanza las tesis fundamentales de L'Ancien Régime et la Révolution, y se

\footnotetext{
${ }^{35}$ Sobre las teorías del contrato social como fundación de la ciencia política moderna y sobre el nexo inseparable que éstas establecen entre libertad y poder, cf. los ensayos recogidos en G. Duso (ed.), Il contratto sociale nella filosofia politica moderna, Milano, Angeli, 1987 [trad. esp. de Marta Rivero, El contrato social en la filosofía política moderna, Valencia, Lesserwelt, 2002]; G. Duso (ed.), Il potere. Per la storia della filosofia politica moderna, Roma, Carocci, 1999. [trad.esp. de Silvio Mattoni, El poder: para una historia de la filosofía política moderna, México, Siglo XXI, 2005] ${ }^{36}$ E. J. Sieyès, Qu'est-ce que le tiers état? (1789), cap. VI. [trad esp. de Mariano Martínez, ¿Qué es el tercer estado?, Barcelona, Edicomunicación, 2003].

${ }^{37}$ Discours de M. de Tocqueville pronocé dans la séance publique du 21 avril 1842, en venant prendre séance à la place de M. le Comte de Cessac, M, p. 262.

${ }^{38}$ El ensayo, en nuestra opinión realmente crucial para comprender a Tocqueville, salió en la London and Westminster Review dirigida por John Stuart Mill.
} 
fundamenta sobre el trabajo de separación que libera a los individuos de la constitución por clases. Cuando la Revolución cancele los últimos vestigios de feudalidad, ésta no hará sino inclinar hacia el futuro, como condición aún por ganar, todo cuanto la monarquía ha realizado desde hace tiempo. Y, esto es, la íntegra despolitización de la sociedad de cuerpos y la institución de una sociedad de libres individuos iguales. "Individuo" y "sociedad" son acuñados, en cuanto conceptos políticos, como los extremos entre los cuales se cumple el proceso constitucional moderno.

6. La máquina constitucional absolutista y el absolutismo del derecho público revolucionario son entonces padrinos de la identificación del sujeto de derecho y, respectivamente, ponen en marcha una dinámica de constante integración de las instancias disociativas propias de una individualización de las relaciones sociales vocacionalmente centrífuga. La moderna sociedad de los "privados" se produce como devorada por dinámicas pasionale ${ }^{39}$ muy distintas de las americanas. La patogénesis originaria del moderno sujeto de derecho ${ }^{40}$ se produce en Europa como rencorosa hacia el lado "aristocrático" -porque es efecto de una nivelación y de una pérdida respecto a un orden de las diferencias y del privilegio-y, sobre el "democrático" como corrompida por la envidia, auténtico motor de una revolución que de política tiende progresivamente a hacerse social. Esta requiere, por tanto, una constante ortopedia política para que el sujeto pueda sostener las nuevas formas de la socialización política.

La existencia del proletariado es la confirmación social de la gran enfermedad que la democracia demuestra ser en el viejo continente ${ }^{41}$. Si en América la tendencia democrática se confirma en condiciones de gobernarse a sí misma, en Europa esta produce, como característica correspondiente, un crecimiento exponencial de los aparatos administrativos del Estado, única instancia capaz de sincronizar el movimiento de un egoísmo de las clases sociales en condiciones de desencadenar crisis violentísimas. Sólo los aparatos ejecutivos del Estado están en condiciones de volver a tener un vínculo entre los individuos y las clases. Sólo el derecho administrativo, en plena codificación en aquellos años ${ }^{42}$, se demuestra capaz de defender una semántica de la "utilidad pública" y de la "razón pública" en la cual recomponer las razones de lo universal.

\footnotetext{
${ }^{39}$ Sobre el sistema de las pasiones de la democracia: O. Le Cour Grandmaison, Haine(s). Philosophie et politique, Paris, PUF, 2002. Pero véase ahora también: C. Colangelo, Uguaglianza immaginaria. Tocqueville, la specie, la democrazia, Napoli, La città del sole, 2008.

${ }^{40}$ Cf. R. Koselleck, Kritik und Krise. Ein Beitrag zur Pathogenese der bürgerlichen Welt, Freiburg i. B. - München, Verlag Karl Alber, 1959. [trad .esp. Crítica y crisis del mundo burgués, Rialp, Madrid, 1965].

${ }^{41} \mathrm{Cf}$. Tocqueville, De la classe moyenne et du peuple (1847), EDP, II, p. 741.

${ }^{42}$ Cf. el para mí importantísimo: Tocqueville, Sur le Cours de droit administratif de Macarel (1846), M, pp. 185-198. Sobre el tema: G. Guglielmi, La notion d'administration publique dans la théorie juridique française (1789-1889), Paris, L.G.D.J, 1991; S. Mannoni, Une et indivisible. Storia
} 
Deriva de esto que la prognosis tocquevilleana sobre el "despotismo democrático" poco tiene que ver con la profecía. Esta deriva más bien de un agudo análisis relativo a las condiciones que anteceden en Europa a la individuación de las relaciones sociales. Cuantos más progresos hagan individualización e igualdad, más crecerá el trabajo de recomposición y de integración del cual el Estado, único titular de una acción "pública", deberá hacerse cargo.

La moderna sociedad de los privados puede ser alcanzada sólo a través de un constante contraste de las tendencias a la dispersión que la trabajan desde dentro. Integrándola y sosteniéndola en términos políticos. Predisponiendo los sujetos a un uso apropiado de su libertad. El Estado actúa por esto, respecto a la sociedad, en la doble figura de instaurador y de garante de la libertad de los ciudadanos ${ }^{43}$. Instaurador, porque es a la sombra del Estado absoluto y de sus aparatos administrativos donde el sujeto moderno elabora y expande su propia autonomía. Garante de esta última porque el trabajo de sincronización y de regulación de la cooperación social de la cual este se hace cargo se demuestra necesario para la propia explicitación de la potencia de autodeterminación del sujeto libre que en ella se identifica.

El concepto de sociedad sirve, en este contexto, para aludir al sistema de relaciones cuasi-naturales que los individuos tejen entre ellos y para definir el campo diseñado por el despliegue de las tecnologías de gobierno que deben ser predispuestas para compensar las "distelelogías" del intercambio. La sociedad es, al mismo tiempo, lo que debe ser gobernado (y que, por tanto, se expone al riesgo de un posible exceso de regulación) y lo que debe ser producido (y que por ello no puede tolerar una $c a$ rencia de integración), actuando de manera que los individuos puedan ser socializados a la altura de la libertad de los modernos ${ }^{44}$. Por un lado, la sociedad como espacio de libre interacción, por el otro, la necesidad de que esta misma libre interacción sea creada, mantenida, organizada -pero no sofocada-, preparando al individuo, liberándolo de la jaula de los status y de los límites que eventualmente le impidan soste-

dell'accentramento amministrativo in Francia, vol. I, La formazione del sistema (1661-1815), Milano, Giuffrè, 1994; vol. II, Dalla contestazione al consolidamento, Milano, Giuffrè, 1996. Me he ocupado ampliamente del tema en: S. Chignola, Fragile cristallo. Per la storia del concetto di società, cit., p. 527 y ss.

${ }^{43}$ Cf. P. Rosanvallon, L'État en France de 1789 à nos jours, Paris, Seuil, 1990.

${ }^{44}$ Cf. G. Burchell, Peculiar Interests: Civil Society and Governing 'The System of Natural Liberty', en: G. Burchell, C. Gordon, P. Miller, The Foucault Effect. Studies in Governamentality, Chicago, The University of Chicago Press, 1991, p. 139 y ss. Pero cf. también S. Chignola, "Líneas de investigación sobre la historia del concepto de sociedad. La conclusión sociológica y la transición gubernamental", Historia Contemporánea, 28, 2004, pp. 33-46. Hemos desarrollado el planteamiento del problema en los Corsi de Michel Foucault al Collège de France en: S. Chignola (ed.), Governare la vita. Un seminario sui Corsi di Michel Foucault al Collège de France (1977-79), Verona, ombre corte, 2006. 
ner el peso de la propia libertad, manteniendo universalmente abiertas para todos las condiciones de la libre autodeterminación.

Cuanto más riesgo corre esta autodeterminación en las clases trabajadoras, tanto más el proceso democrático deberá ser gobernado.

7. Es sobre las modalidades de este gobierno donde se juega de verdad la partida. O una creciente intervención del Estado -el despotismo "souple" de un poder público paterno, vigilante, invasivo e infantilizador enraizado sobre la continuidad entre antiguo régimen y Revolución por la acumulatividad de la actuación administrativa ${ }^{45}$-, o una economía moral de la democracia, de la cual se hacen cargo las clases superiores, en la cual se gestione el "apprentissage" individual de la libertad de las clases del trabajo. Sólo un esquema de "soins paternels" para la democracia está en condiciones de rescatar el aislamiento de los individuos y la atomización de las relaciones sociales.

Si la revolución de la igualdad es una tendencia incontenible e imparable, ésta puede, sin embargo, ser corregida. Su instinto salvaje, la pulsión irrefrenable que pone en riesgo los pilares de la civilización burguesa, propiedad y cultura, en el socialismo incubado en la reivindicación de los derechos de 1848, pueden ser disciplinados, no obstaculizados, sólo actuando sobre la línea diseñada por la tendencia aislada como motor de la democracia. Tocqueville considera que sólo una extensión del disfrute de los derechos políticos acompañada por el apoyo ofrecido al principio de libre asociación puede representar la alternativa a una invasiva intervención administrativa del Estado.

Se trata, de nuevo, de disciplinar la tendencia, de endulzarla. No de obstaculizarla. Es necesario actuar sobre el cuerpo de las pasiones democráticas: es necesario ejercer un impulso sobre el principio de interés y sobre el deseo de adquisición para que los individuos liberados por el proceso de descomposición de la societas civilis puedan aprender y experimentar la noción de un interés común y dar concreción a la idea abstracta de libertad. Es necesario favorecer, no obstaculizar, las asociaciones libres. Se requiere al proletariado en la libre propiedad. Es necesario conceder a todos los derechos políticos para que puedan experimentar qué significa de verdad ser libres y deben asumir individualmente la responsabilidad de esta libertad. Porque la democracia es como un adolescente inquieto que debe ser corregido para introducir elementos teleológicos y de orden -según un cálculo colectivo y, por eso, "político"

\footnotetext{
${ }^{45}$ Véase: P. Legendre, Trésor historique de l'État en France. L'administration classique, Paris Fayard, 1992.

${ }^{46}$ DAI, Introduction, p. 5: "la démocratie a été abandonnée à ses instincts sauvages; elle a grandi comme ces enfants, privés des soins paternels, qui s'élèvent d'eux-mêmes dans les rues de nos villes, et que ne connaissent de la société que ses vices et ses miséres".
} 
de interés bien entendido. Se trata así de remontar el proceso indomable que se ha producido de erosión de los equilibrios de larguísimos periodos en la constitución material de la sociedad mediante la maduración de las costumbres y las ideas o a través de la práctica de la democracia ${ }^{46}$.

Sólo así, rescatando, entonces, su origen tutelar y absolutista con la progresiva emancipación de sus nuevos protagonistas sociales, la tendencia democrática podrá ser estabilizada y capacitada para el autogobierno en Europa. No se trata de hacer renacer una sociedad aristocrática o conservada a través de un sistema de diferencias basado en el compromiso entre igualdad y "capacite", sino de valorizar, en cambio, la libertad que existe dentro de las sociedades democráticas que la teodicea de un progreso invencible impone como nueva época del mundo ${ }^{47}$.

Hecho por Dios ni esclavo ni omnipotente, el moderno sujeto de derecho debe adecuarse a un principio de realidad acotado en términos de reconocimiento y de reciprocidad. Debe aceptar virilmente el "cercle fatal" que los otros individuos trazan con su indisponible ejercicio de la libertad en torno a él y a su igualmente indisponible derecho a la propia libertad. Haciéndolo, descubrirán los amplios horizontes en los cuales ejercitar la potencia que la historia les ha conquistado ${ }^{48}$. Porque igualdad y derecho sin práctica de la libertad bien poco quieren decir, a los ojos de Tocqueville.

${ }^{47}$ DAII, IV, cap. 7, p. 328.

${ }^{48}$ DAII, IV, cap. 8, p. 339. 